\title{
Migração e Mobilidade Social: revisitando a discussão a partir da Pnad 2014
}

\author{
Paulo Jannuzzi ${ }^{1}$ \\ Paula Montagner ${ }^{2}$ \\ Edna Taira ${ }^{3}$
}

\section{Introdução}

A perspectiva de mobilidade social é um dos fatores importantes para explicação da migração de média e longa distância no Brasil Contemporâneo. Seja na ótica neoclássica de entender a migração como resposta a desequilíbrios regionais de oferta de empregos e renda, seja no paradigma histórico-estrutural de migração como decorrência de fatores de expulsão em regiões menos dinâmicas e vulneráveis, ou ainda na perspectiva da migração como um fenômeno sustentado pelas redes de sociabilidade, a direção e intensidade dos fluxos migratórios tem alguma relação com as possibilidades de inserção virtuosa no mercado de trabalho na área de destino .

Essa é a hipótese de trabalho de que parte esse estudo, valendo-se de experiência anterior de análise da vinculação entre migração, dinâmica regional e mobilidade socioocupacional no Estado de São Paulo nos anos 1980 (JANNUZZI 2000). Nesse trabalho procura-se demonstrar que a migração continua sendo um "determinante" relevante da mobilidade social no país, viabilizando a inserção e/ou mobilidade socioocupacional para seus protagonistas. A persistência de diferenças expressivas da estrutura e oportunidades ocupacionais pelas regiões do país, a existência de redes familiares e sociais ligando-as, a ampla disponibilidade de meios de transporte e comunicação no território, o forte dinamismo da economia e ampliação do escopo e escala das políticas sociais configuraram um ambiente em que a mobilidade territorial de indivíduos possibilitou ascensão ocupacional no destino para parte expressiva daqueles que a empreenderam.

O texto está estruturado em duas seções, iniciando com uma recensão histórica sobre mobilidade social no país, com base em três das edições em que a Pesquisa Nacional por Amostra de Domicílios (PNAD) investigou o tema em questionários suplementares1982, 1996 e 2014. Esses levantamentos refletem momentos distintos da economia

\footnotetext{
${ }^{1}$ Professor da Escola Nacional de Ciências Estatísticas do IBGE. Pesquisador CNPq no projeto "Políticas Públicas, Mudança Social e Dinâmica Demográfica no Brasil de 1992 a 2014” .E-mail: paulo.jannuzzi@ibge.gov.br .

${ }^{2}$ Economista, Assessora Técnica da Fundação SEADE. E-mail: pmontagner54@gmail.com

${ }^{3}$ Estatística da Fundação Seade. E-mail:etayra@gmail.com
} 
nacional, da dinâmica regional do emprego e também da oferta de políticas públicas, configurando contextos diferenciados de mobilidade social e de deslocamentos populacionais. Em seguida apresenta-se descritivamente os resultados da mobilidade social segundo diferentes localidades de residência e fluxos de migrantes, tal como captados pela PNAD 2014. Como apêndice do trabalho é apresentada a estrutura de categorias sócio-ocupacionais em que as ocupações foram classificadas, compatibilizada nos três momentos da pesquisa, para permitir uma análise temporal consistente do fenômeno.

\section{Mobilidade Social no Brasil: uma análise dos últimos 50 anos}

Mobilidade social é um constructo sociológico entendido como a mudança de conjunto de indivíduos de uma posição social para outra, em um dado período de referência, entendendo posição social como uma condição de renda, classe socioeconômica ou mais comumente como status da sua inserção ocupacional (BOUDON; BOURRICAUD 2001).

A análise de mudanças ocupacionais é o método clássico de realizar estudo de mobilidade social, pelo fato da condição profissional ser um indicador mais robusto e estável da posição de um indivíduo na estrutura social. A renda pode ser uma variável mais volátil em diversas sociedades e de mais difícil recordação em levantamentos empíricos sobre mobilidade. Assim, mobilidade social confunde-se na maioria dos estudos com mobilidade sociocupacional, e do ponto de vista metodológico, desdobra-se na análise de transições de ocupação entre dois momentos de referência. Mobilidade intrageracional é, neste sentido, o movimento do indivíduo em duas diferentes fases do seu ciclo de existência, no início da sua atividade profissional e no momento atual ou de sua aposentadoria, por exemplo. Mobilidade de carreira diferencia-se da anterior por representar um dos possíveis episódios de mudança ocupacional entre dois momentos específicos, em geral, situações marcantes da econômica nacional, plano econômico ou mudanças da legislação trabalhista. Há ainda a Mobilidade intergeracional, se, em vez disso, se confronta a profissão de um indivíduo com a profissão do pai no início de sua vida profissional.

A mobilidade pode ser horizontal ou vertical. Se a passagem de uma posição social para outra não muda a sua condição de classe ou status ocupacional, a mobilidade é dita horizontal. Mobilidade vertical, ao contrário, significa a transição para uma situação melhor em termos de renda ou prestígio ocupacional - mobilidade ascendente- ou pior - 
mobilidade descendente. Imobilidade, como o nome o revela, é a situação de permanência na mesma ocupação, estrato sociocupacional ou padrão de renda no período de tempo considerado.

Os determinantes da mobilidade social são apontados nos estudos clássicos como a industrialização, urbanização e acesso à escolarização. $\mathrm{O}$ crescimento da indústria e a urbanização provocam mudanças intensas no espectro ocupacional, com criação de novas e diferentes ocupações, e também a diminuição e desprestígio de outras mais tradicionais. Ocupações de serviços passam a se expandir mais rapidamente que postos de trabalho no campo, de menor remuneração e prestígio. Os fluxos migratórios do campo para cidade provocam o aumento da mobilidade, em parte horizontal, outra parte vertical e ascendente. $\mathrm{O}$ acesso a escolarização potencializa, para determinados grupos, a possibilidade de ascensão a ocupações técnicas e outras mais especializadas no meio urbano, ampliando o circuito da mobilidade ocupacional.

Esses são os processos que Pastore \& Valle Silva (2006) propuseram para entendimento da intensidade e padrão da mobilidade social no país. Segundo os autores, a formação da sociedade urbano-industrial brasileira no século XX teria sido acompanhada de intenso processo de mobilidade social ascendente, em que a maior parte da população economicamente ativa teria galgado postos de trabalho urbanos, não manuais ou de maior qualificação, como resultado das mudanças estruturais induzidas pela industrialização, migração rural-urbana e ampliação da oferta educacional por que passou a sociedade brasileira no período. De um lado, a expansão da indústria e seus efeitos dinamizadores sobre toda a economia atuariam, ao longo das décadas, para a criação e oferta de postos de trabalhos na própria indústria, no comércio, nos transportes, nos serviços, na administração pública e, enfim, em outras ocupações urbanas, não manuais e de maior qualificação. De outro lado, a migração rural-urbana e a ampliação das oportunidades educacionais viriam a atender à demanda por mão-de-obra induzida pelos efeitos sinérgicos dos investimentos industriais e do crescimento dos centros urbanos, como em um processo funcional de integração das massas camponesas mal qualificadas em ocupações urbanas do baixo terciário e dos estratos médios mais escolarizados nos postos de trabalho de maior especialização técnica.

Embora intensa, a mobilidade social no país teria se caracterizado por se concentrar na base da pirâmide social, por forte herança de status de classe de origem e pelas curtas distâncias sociocupacionais percorridas, outro achado recorrente nos trabalhos da área. Tal padrão aparentemente antitético de mobilidade - em que muitos 
ascenderam pouco e poucos ascenderam muito na pirâmide social - seria resultado da natureza restrita da mobilidade sociocupacional dos trabalhadores rurais e de seus filhos. Para a grande maioria dos volumosos fluxos de trabalhadores de enxada que chegavam do campo, as oportunidades ocupacionais acabaram se restringindo às ocupações de baixa remuneração e qualificação no mercado de trabalho urbano, na prestação de serviços, serviços domésticos e construção civil (JANNUZZI 2002).

De fato, essas são as características gerais que se pode inferir da análise da mobilidade social nos três levantamentos anteriormente mencionados na PNAD. Na perspectiva da mobilidade intergeracional- comparação das posições sociocupacionais entre pais (aos 15 anos dos filhos) e moradores responsáveis de 15 a 74 anos (no momento da pesquisa) - verifica-se que a maior parcela dos indivíduos ascenderam em relação aos seus pais (Tabela 1). Parcela menor de indivíduos ficaram imóveis ou vieram a ocupar posições ocupacionais mais baixas que seus país. Vale observar que no último período (2014), a mobilidade ascendente retoma os níveis identificados em 1982, depois da queda identificada em 1996.

A diferença de conjuntura econômica nos períodos que antecedem os levantamentos -e o reflexo sobre o dinamismo do mercado de trabalho em cada contextocertamente explica boa parte dessas variações (além do comportamento da migração inter-regional e acesso à educação, como mencionado anteriormente). Assim, os efeitos do maior ou menor dinamismo do emprego e maior ou menor diversificação ocupacional do "Milagre" nos anos 1970, da "Década Perdida" nos anos 1980 e do "Crescimento de Massa" nos anos 2000 traduzem-se no comportamento das taxas de mobilidade ascendente captadas nas edições da PNAD: em 1982, 49\% dos filhos haviam ascendido sócio-ocupacionalmente em relação ao pais; em 1996, a cifra equivalente caíra para 41\%; em 2014, nova retomada, já que 50\% dos filhos exibiam situação socio-ocupacional melhor que a dos pais. A mobilidade descendente não segue, contudo, tendência simétrica: aumenta em todo o período, de 4\% para $11 \%$ entre 1982 e 1996, chegando em 13\% em 2014. Parcela dos filhos, provavelmente de estratos médios da estrutura social, não conseguiram replicar a trajetória de ascensão dos pais, vindo a ocupar postos de trabalho de status mais baixo ou de igual posição na escala sócio-ocupacional ao longo do período.

Conclusões semelhantes podem ser derivadas da análise dos indicadores de mobilidade intrageracional (comparação do primeiro emprego e emprego atual do indivíduo). Em 1982, a PNAD apontou que pouco mais da metade (52\%) dos indivíduos 
(homens, responsáveis dos domicílios, com idade entre 15 a 74 anos) tiveram trajetória ascendente no mercado de trabalho. Tal fato decorreria do dinamismo econômico do "Milagre" nos anos 1970, com seus efeitos sobre as demandas por ocupações na indústria, comércio e serviços, além da intensificação da migração rural-urbana e dos fluxos do Norte/Nordeste em direção à São Paulo e Rio de Janeiro desde os anos 1950. Somente $4 \%$ dos indivíduos estava em posição pior na escala socio-ocupacional entre o primeiro emprego e o atual em 1982.

As baixas taxas de crescimento econômico e do emprego nos anos 1980 e em boa parte da década seguinte significaram a redução das chances de se conseguir postos de trabalho com status igual ou superior: em 1996, a mobilidade intrageracional ascendente havia caído para $42 \%$ e a descendente ampliado para $13 \%$ ! O forte dinamismo do emprego formal - 20 milhões de empregos formais pela Relação Anual de Informações Sociais (RAIS) entre 2004 e 2014- e a ampliação de postos de trabalho de nível técnico e superior, seja para atender demandas de uma economia urbana mais complexa, assim como também de uma matriz mais diversificada de serviços públicos, certamente explicam a retomada dos níveis de mobilidade ascendente do passado: em 2014, 52\% dos indivíduos lograram ascender em relação ao primeiro emprego formal (e uma cifra menor, de $8 \%$, haviam descido em termos sociocupacionais).

Tabela 1: Mobilidade Social segundo anos de levantamento Responsáveis pelo domicílio homens de 15 a 74 anos Brasil 1982, 1996 e 2014

\begin{tabular}{clcc}
\hline Ano & Mobilidade & Intergeracional & Intrageracional \\
\hline \multirow{2}{*}{1982} & Ascendente & $49,1 \%$ & $52,0 \%$ \\
& Imóvel & $42,5 \%$ & $44,1 \%$ \\
& Descendente & $8,4 \%$ & $3,9 \%$ \\
\hline \multirow{2}{*}{1996} & Ascendente & $47,6 \%$ & $41,5 \%$ \\
& Imóvel & $41,0 \%$ & $45,9 \%$ \\
& Descendente & $11,4 \%$ & $12,6 \%$ \\
\hline \multirow{2}{*}{2014} & Ascendente & $50,5 \%$ & $52,2 \%$ \\
& Imóvel & $36,6 \%$ & $39,7 \%$ \\
& Descendente & $12,9 \%$ & $8,1 \%$ \\
\hline
\end{tabular}

Fonte: Jannuzzi (2002) e Processamento próprio da PNAD para 2014

A análise da estrutura de ocupações geradas mostra a continuidade da eliminação de postos de trabalho nas atividades produtivas de agricultura e pecuária, tendo como contrapartida não apenas ocupações urbanas nos serviços, indústria e serviços, que envolveram nível superior. Entre 2004 e 2014, verificou-se substancial elevação de 
ocupações que envolvem os serviços educacionais - com a contratação de professores, coordenadores de ensino, supervisores, diretores da pré-escola até o ensino superior - no setor público mas igualmente no setor privado. Além disso, aumentou substantivamente a presença profissionais da área de saúde e de assistência social em todos os municípios, além de seu crescimento em centros urbanos em que se fortaleceu a cadeia de serviços do setor - exames biológicos e de imagem, além de hospitais com diferentes graus de especialização. Aqui a presença de escolas de nível superior tem um papel fundamental na organização de núcleos produtores de novas pesquisas na área de saúde, com forte concentração em São Paulo.

Chama a atenção ainda a substancial elevação de contratações formalizadas, com elevada rotatividade, mas com crescimento no tempo de emprego e por isso mesmo com ampliação da capacidade de ampliar planejamento das famílias, o que somado à ampliação de crédito, permitiu não apenas ampliar consumo, mas igualmente ampliar o tempo de estudo dos membros das famílias, não apenas os mais jovens.

\section{Migração e Mobilidade Social: resultados em 2014}

A análise das informações consideradas as diferentes regiões vai apontar para um dos aspectos mais importantes desse processo. Ele foi generalizado, uma vez que estava calcado na possibilidade de ampliação do acesso a postos de trabalho de melhor remuneração - como empregados no setor privado e público, mas igualmente na organização de novos serviços em todas as cidades, que apostaram assim em novos hábitos urbanos e assim alteraram padrões de compras e consumo de serviços. 
Tabela 2: Mobilidade Intrageracional segundo regiões de residência selecionadas Responsáveis pelo domicílio homens de 15 a 74 anos Brasil 2014

\begin{tabular}{lccc}
\hline Região & Ascend & Imob & descend \\
\hline Norte & $48,4 \%$ & $44,4 \%$ & $7,2 \%$ \\
Nordeste & $45,6 \%$ & $47,1 \%$ & $7,2 \%$ \\
NE Metropolitano & $49,7 \%$ & $40,4 \%$ & $9,9 \%$ \\
Sudeste & $53,6 \%$ & $37,3 \%$ & $9,1 \%$ \\
$\quad$ Estado de SP & $59,0 \%$ & $32,2 \%$ & $8,8 \%$ \\
$\quad$ RMSP & $63,7 \%$ & $29,7 \%$ & $6,7 \%$ \\
Sul & $58,5 \%$ & $34,0 \%$ & $7,4 \%$ \\
Centro-Oeste & $56,3 \%$ & $35,6 \%$ & $8,1 \%$ \\
$\quad$ DF & $54,9 \%$ & $34,3 \%$ & $10,8 \%$ \\
Total & $52,2 \%$ & $39,7 \%$ & $8,1 \%$ \\
\hline
\end{tabular}

No caso das regiões metropolitanas, a presença de setores industriais que contrataram e investiram na ampliação da escolaridade dos seus empregados como forma de ampliar sua produtividade a situação foi marcada no período 2004-2010, ainda que tenha prosseguido a ampliação da parcela de jovens que buscava uma formação de maior especialização até 2014.

A combinação de maior escolaridade e geração de empregos, com salários crescendo, inclusive para aqueles que estavam sinalizados pelo salário mínimo, promoveu uma articulação virtuosa que os dados de mobilidade expressão de forma sintética, mas igualmente clara.

Regionalmente, os aumentos são menores no Norte e Nordeste, cujas especificidades tornam sempre lenta a ampliação do ritmo produtivo e foi mais intenso nas regiões $\mathrm{SE}$ e Sul, com o $\mathrm{CO}$ crescendo inclusive de forma mais intensa do que o DF, graças ao crescimento das cidades da região nas atividades de serviços e comércio.

De todo modo o que impressiona é que todo esse crescimento foi muito forte na RMSP, região madura do ponto de vista industrial e de comercio e serviços, mas que aproveitou toda a capacidade instalada e modernizou sua produção, apoiada pelas novas possibilidade de importar novos tipos de insumos e assim propiciar a descentralização de novos polos produtivos em seu entorno, fortalecendo o crescimento do Estado de São Paulo como um todo. Vale lembrar que São Paulo neste período, já contava com migração pendular importante na RMSP e que houve aumento substantivo de emigração de população andina e asiática, na maior parte das vezes sempre trazendo pessoas com 
maior escolaridade e maior especialização para as diferentes áreas, mas igualmente pessoas dispostas a trabalhar em situações difíceis e assemelhadas ao trabalho escravo, com expectativas de que suas famílias tivessem melhores condições.

Tabela 3: Mobilidade Intrageracional por condição de migração ou fluxo migratório Responsáveis pelo domicílio homens de 15 a 74 anos Brasil 2014

\begin{tabular}{lccc}
\hline Região & ascend & Imob & descend \\
\hline Nunca migraram para outra UF & $55,4 \%$ & $37,4 \%$ & $7,2 \%$ \\
Migrantes interestaduais residentes há 4 anos & $52,1 \%$ & $38,3 \%$ & $9,6 \%$ \\
Migrantes interestaduais residentes de 5 a 9 anos & $57,1 \%$ & $31,3 \%$ & $11,6 \%$ \\
Migrantes interestaduais residentes há + 10 anos & $57,4 \%$ & $34,8 \%$ & $7,8 \%$ \\
Nascidos no NE e residentes na RMSP & $68,7 \%$ & $29,8 \%$ & $1,4 \%$ \\
Nascidos no NE e residentes no interior SP & $53,1 \%$ & $34,6 \%$ & $12,3 \%$ \\
Nascidos no NE e residentes fora do estado SP & $55,0 \%$ & $36,9 \%$ & $8,1 \%$ \\
Nascidos no NE e residentes no SE exceto SP & $51,4 \%$ & $37,1 \%$ & $11,5 \%$ \\
Nascidos no NE e residentes no CO e Norte Urb & $59,2 \%$ & $34,6 \%$ & $6,1 \%$ \\
Nascidos no NE e residentes no DF & $51,4 \%$ & $36,1 \%$ & $12,5 \%$ \\
Nascidos e sempre residentes no NE & $49,0 \%$ & $44,7 \%$ & $6,3 \%$ \\
Nascidos e residentes no NE, já moraram outra UF & $50,2 \%$ & $40,0 \%$ & $9,8 \%$ \\
Nascidos no NE e residentes no NE metropolitano & $57,0 \%$ & $31,6 \%$ & $11,4 \%$ \\
Nascidos no NE e residentes fora NE & $59,7 \%$ & $34,0 \%$ & $6,3 \%$ \\
Nascidos no Sul e residentes no CO e Norte Urb & $67,7 \%$ & $27,6 \%$ & $4,7 \%$ \\
Nascidos no Sul e residentes fora Sul & $60,0 \%$ & $32,1 \%$ & $7,9 \%$ \\
Total & $52,2 \%$ & $39,7 \%$ & $8,1 \%$ \\
\hline
\end{tabular}

\section{Considerações finais}

A análise da mobilidade social por região ou local de moradia aponta para forte mobilidade ascendente em áreas de forte intensidade migratória e estruturação do mercado de trabalho nos últimos 50 anos. Seja pelas oportunidades ocupacionais mais diversas e amplas do mercado de trabalho metropolitano, seja pela baixa posição ocupacional no início da carreira, 64\% dos residentes na RMSP em 2014 lograram ascender ao longo da trajetória profissional. É nessa região aonde estão também os níveis mais baixos de imobilidade e mobilidade descendente. Esse resultado certamente reflete, de um lado, os efeitos da migração originária no $\mathrm{NE}$ em direção à região nas últimas décadas do século $\mathrm{XX}$, assim como da evasão ou retorno daqueles que tiveram maior dificuldade de aí se estabelecerem. O dinamismo do setor de Construção Civil nos anos 
2000 também deve ter favorecido a mobilidade ascendente, assim como a criação de postos de trabalhos em setores mais modernos da economia metropolitana. Explicação semelhante pode se aplicar ao interior paulista e região Centro-Oeste, que também apresentam mobilidade ascendente acima da média Brasil.

A análise da mobilidade social segundo origem do responsável corrobora a tese da ascensão comparativamente elevada de migrantes nordestinos em direção à RMSP e Centro-Oeste. Cerca de $69 \%$ dos responsáveis nascidos no NE que residiam na RMSP haviam logrado ascender em relação ao primeiro emprego. Menos de $2 \%$ deles apresentaram descenso ocupacional, o que, por outro lado, parece reforçar a hipótese de que os resultados da mobilidade social se explicam também pela evasão daqueles com maior dificuldade de se manter na região. Também corrobora essa hipótese o fato de que migrantes com maior tempo de residência apresentam chances de mobilidade ascendente mais elevadas.

Mas não foi apenas a RMSP que oportunizou mobilidade social para migrantes nascidos no NE. Ter migrado do NE para outros estados ou para as regiões metropolitanas nordestinas também viabilizou oportunidades de ascensão para seus protagonistas, em geral. Enquanto que quase $60 \%$ daqueles que saíram do NE ascenderam socioocupacionalmente, entre os nordestinos que sempre residiram na região a parcela que logrou mobilidade ascendente não chegou a 50\%. Migração para Centro-Oeste e Norte também ampliou as oportunidades de inserção mais virtuosa. Mas vale destacar que $57 \%$ dos nordestinos nascidos e residentes nas regiões metropolitanas nordestinas ascenderam.

Tendências semelhantes de evolução das cifras de mobilidade - queda em 1996, seguida de aumento em 2014- foram constatadas por Ribeiro (2017). Analisando o processo de mobilidade intergeracional a partir de amostra de responsáveis homens com 30 a 50 anos e com uma escala socio-ocupacional de com nove estratos, o autor aponta que, em 1988, a mobilidade ascendente alcançou 34\%, caindo em 1996 para 32\%, voltando a subir para $34 \%$ em 2014. Tais resultados, ainda que diferentes em termos de intensidade do aqui reportado - pelos distintos grupos etários e escalas de ocupações usadas nos dois estudos- parecem corroborar a importância aludida ao dinamismo do mercado de trabalho nos anos 2000 sobre as possibilidade de ascensão sócio-ocupacional recente no país.

Há certamente muito a ser analisado ainda acerca da mobilidade social recente no país e suas vinculações com a dinâmica do mercado de trabalho, migração e também com as políticas sociais. A expansão de vagas em ocupações técnicas e de nível superior 
vinculadas à ampliação da escala de escopo das políticas sociais por todo o território nacional, a oferta educacional mais ampla em todos os níveis de ensino- inclusive a técnica-profissional - chegando nos municípios mais pobres e menos dinâmicos, combinados com políticas distributivas, compensatórias e afirmativas para acesso ao ensino superior - público e privado- parecem ter tido papel ainda pouco estudado nesse processo.

Os resultados desse trabalho sugerem que essa investigação é certamente instigante e relacionada a outros tantos processos sociais e econômicos transcorridos nos últimos 50 anos e, em particular, com mudanças nas chances de inserção e ascensão profissional de parcelas significativas de população oriunda de estratos de menor renda e qualificação depois de 2003. 


\section{Apêndice metodológico: Escala Sóciocupacional empregada}

O objetivo desse apêndice é registrar os esforços relativos à definição da escala sóciocupacional compatível com a usada em estudo anterior, com base nos dados da Pnad 1982 e 1996 (Jannuzzi 2002). A ideia de empregar a mesma escala do estudo anterior era a de permitir uma análise comparativa dos índices de mobilidade social apresentados anteriormente, de modo a responder uma pergunta básica: o crescimento econômico, aumento do emprego formal, diversificação da estrutura ocupacional, ampliação das oportunidades de formação técnica e superior, conjugado com ampliação de outras políticas sociais redistributivas, compensatórias e/ou afirmativas nos anos 2000, em especial entre 2004 e 2014, teriam impacto positivamente nas possibilidades de ascensão sociocupacional da população brasileira, comparativamente ao aumento da imobilidade e mobilidade descendente constatado na Pnad 1996 (em relação à Pnad 1982)?

Vale registrar que as ocupações têm sido registradas de modo crescentemente detalhado nas pesquisas do IBGE, culminando com uso da $\mathrm{CBO}$-domiciliar no Censo Demográfico 2000, acompanhando as mudanças na estrutura ocupacional e normativatrabalhista do país ${ }^{4}$. As PNADs têm seguido o sistema classificatório de ocupações e setores de atividade econômica do Censo, empregando, pois, três sistemas diferentes ao longo de seus quase cinquenta anos de pesquisa. Na Pnad 1972, edição em que se realizou o primeiro levantamento em larga escala de mobilidade social no país, foi usado um sistema classificatório de 268 ocupações. Na Pnad 1982, outro sistema mais detalhado foi usado, com 381 ocupações, resolvendo algumas questões com forte impacto nos estudos de mobilidade, com a diferenciação entre trabalhadores agrícolas de produtores agropecuários, entre outros aprimoramentos. Com a introdução da CBO-Domiciliar a partir de 2002 na pesquisa, ampliou-se bastante a capacidade de discriminação de situações de inserção ocupacional, com detalhamento de 510 famílias ocupacionais, em especial aquelas com perfil técnico, de supervisão/gerencial e de nível superior.

\footnotetext{
${ }^{4}$ Vale registrar que as classificações ocupacionais foram sempre um tema complexo nos Censos Demográficos desde sua criação. Barreto (2009) compilou as diversas classificações empregadas desde o Censo de 1972 (com 37 possibilidades de resposta para ocupação), passando pelo Censo de 1940 (com 718 categorias) até o Censo 2000 (com seus pouco mais de 500 códigos ocupacionais).
} 
Quadro 1 - Sistemas de Classificação de Ocupações e Setores de Atividade Econồmica Brasil, 1960 a 2010

\begin{tabular}{|lrrrrrr|}
\hline Censos Demográficos & $\mathbf{1 9 6 0}$ & $\mathbf{1 9 7 0}$ & $\mathbf{1 9 8 0}$ & $\mathbf{1 9 9 1}$ & $\mathbf{2 0 0 0}$ & $\mathbf{2 0 1 0}$ \\
& & & & & & \\
Número de ocupações registradas & 247 & 268 & 381 & 381 & 510 & 510 \\
Número de Setores de atividade & 133 & 154 & 169 & 169 & 224 & 224 \\
\hline
\end{tabular}

Para fins de elaboração de estudos comparados de mobilidade social entre $1982 \mathrm{e}$ 1996 foi desenvolvida a escala apresentada em Jannuzzi (2000). A proposta original era a de comparar também com resultados da Pnad 1972, tarefa não possibilitada pelas dificuldades de compatibilização entre as estruturas ocupacionais nos dois períodos em uma mesma escala (em especial, as ocupações do campo).

Visando a realização de estudos comparados da estrutura socioocupacional ao longo dos últimos 40 anos, desenvolveu-se uma nova escala com os mesmos parâmetros metodológicos para uso na PNAD após 2002, apresentada em Jannuzzi (2004), com base na Classificação Brasileira de Ocupações de 2002, a partir de informações levantadas no Censo Demográfico de 2000. As duas escalas socio-ocupacionais foram desenvolvidas por meio da aplicação de técnicas multivariadas a partir do rendimento e escolaridade típicos, como proposto em Jannuzzi (1999). Na escala socio-ocupacional proposta para as 510 ocupações da CBO 2002 empregou-se ainda, para juízo técnico ex-post, indicadores de precarização ocupacional. Esses indicadores foram usados para decisão do estrato socio-ocupacional de ocupações situadas nas fronteiras de um estrato e outro tais como o grau de informalidade do trabalho dos ocupados (proporção de empregados sem carteira), grau de proteção social (proporção de ocupados sem contribuição à previdência), grau de contapropismo (medido como a razão de indivíduos conta-própria por empregador, para as famílias ocupacionais que admitem tais categorias), jornada total estendida ( proporção de indivíduos que, em todas as ocupações, trabalham 49 horas ou mais por semana) e um indicador de sobretrabalho (proporção de ocupados com 2 ou mais trabalhos).

O uso combinado das duas escalas socioocupacionais, construídas sob mesmos princípios metodológicos, permite visualizar a mudança da estrutura ocupacional agregada no país ao longo dos últimos vinte e cinco anos, com forte diminuição das ocupações rurais e urbanas de baixa qualificação (estrado 5, baixo status) e aumento das demais, em especial, as de maior qualificação técnica e de nível superior ou comando hierárquico (estratos médio-alto e alto). 
Gráfico 1: Estrutura socioocupacional em 5 estratos de ocupações agrupadas segundo rendimento e escolaridade típicos - Brasil 1992 a 2014.

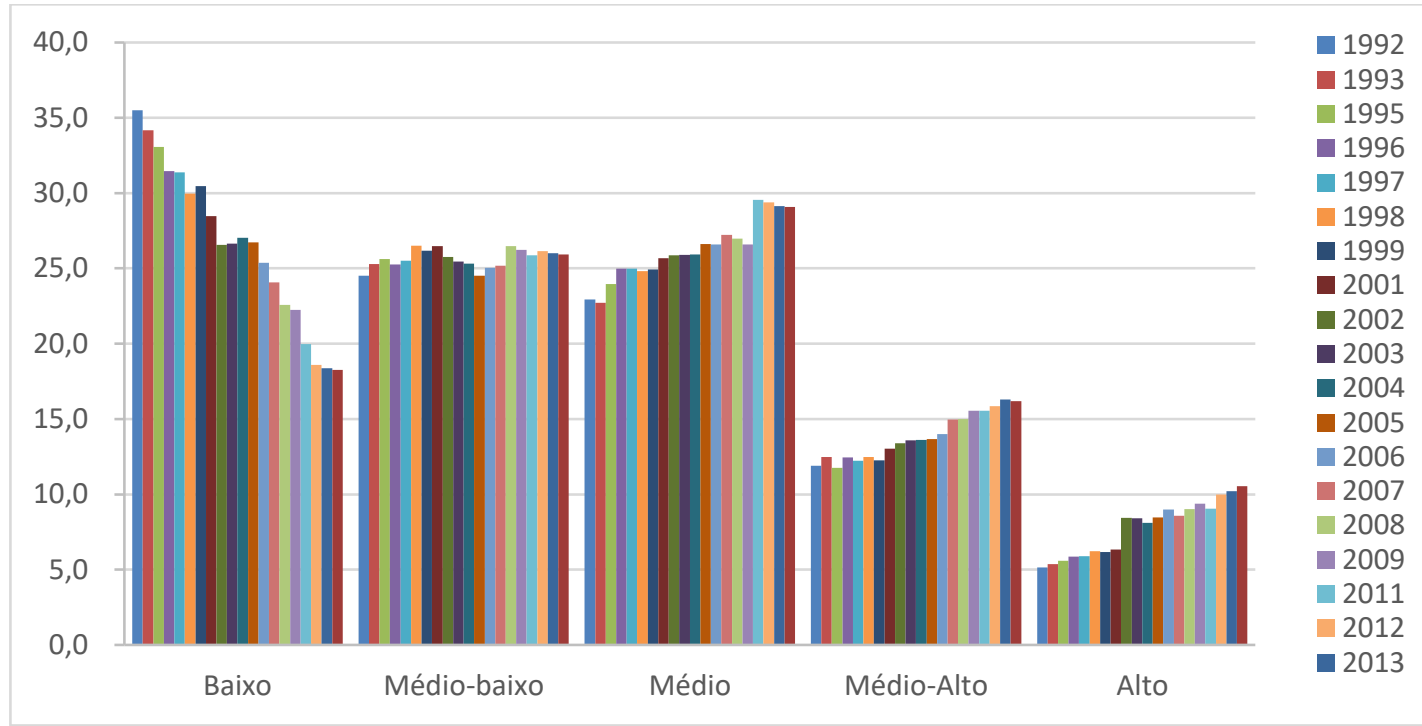

Tabela 1: Variação relativa dos Estratos Socioocupacionais em períodos segundo Regiões Brasil 1992 a 2014

\begin{tabular}{|c|c|c|c|c|c|c|c|}
\hline & Período & Alto & $\begin{array}{l}\text { Médio- } \\
\text { alto }\end{array}$ & Médio & $\begin{array}{l}\text { Médio- } \\
\text { baixo }\end{array}$ & Baixo & Total \\
\hline \multirow[t]{2}{*}{ Brasil } & Var 92-01 & 44,0 & 28,5 & 31,2 & 26,7 & $-6,0$ & 17,2 \\
\hline & Var 04-14 & 51,7 & 38,7 & 30,9 & 19,4 & $-21,1$ & 16,7 \\
\hline \multirow[t]{2}{*}{ COeste } & Var 92-01 & 49,2 & 20,0 & 42,2 & 35,6 & $-9,0$ & 20,5 \\
\hline & Var 04-14 & 64,9 & 52,4 & 37,7 & 28,3 & $-20,5$ & 26,8 \\
\hline \multirow[t]{2}{*}{ Nordeste } & Var 92-01 & 37,4 & 51,2 & 27,7 & 33,6 & $-6,5$ & 13,3 \\
\hline & Var 04-14 & 49,6 & 44,7 & 44,3 & 25,9 & $-22,9$ & 12,1 \\
\hline \multirow[t]{2}{*}{ Norte } & Var 92-01 & 39,1 & 34,4 & 52,2 & 65,8 & 32,7 & 47,6 \\
\hline & Var 04-14 & 64,4 & 51,0 & 43,6 & 19,8 & $-11,8$ & 20,1 \\
\hline \multirow[t]{2}{*}{ Sudeste } & Var 92-01 & 47,5 & 20,9 & 27,6 & 21,0 & $-5,1$ & 18,1 \\
\hline & Var 04-14 & 50,1 & 34,2 & 24,1 & 16,4 & $-17,1$ & 19,3 \\
\hline \multirow[t]{2}{*}{ Sul } & Var 92-01 & 39,0 & 27,3 & 36,5 & 20,2 & $-11,2$ & 13,3 \\
\hline & Var 04-14 & 48,6 & 34,7 & 25,8 & 12,3 & $-29,1$ & 11,3 \\
\hline
\end{tabular}

Há certamente algumas descontinuidades a ressaltar nessa série, como a observada em 2002 no estrato 1 (decorrente do detalhamento de ocupações de nível superior da CBO-Domiciliar); em 2011 no estrato 3 e em 2006 no estrato 4 (a serem melhor investigados). Mas de modo geral, pode-se observar uma tendência consistente ao longo do período, como se pode observar nas taxas de crescimento dos estratos entre 1992 a 2001 e 2004 a 2014 (2002 a 2003 foram excluídos para que se pudesse compatibilizar as amostras das Pnads anos 90 e anos 2004 em diante, quando a área rural da antiga Região Norte (exclusive Tocantins) não era captada na pesquisa). A regularidade nas taxas de crescimentos dos estratos se mantem nos dois períodos nas 5 Grandes Regiões, inclusive 
(e também em estados populosos como São Paulo, Minas, Rio de Janeiro, Bahia, Pará, Rio Grande do Sul, Distrito Federal, para citar os principais).

O emprego dessa estrutura socioocupacional para análise exploratória da mobilidade social, levantada na Pnad 2014, levou a produção das seguintes tabelas inter e intrageracional

Tabela 2: Matriz de Mobilidade Social com emprego da escala Jannuzzi (2004)

\begin{tabular}{|c|c|c|c|c|c|c|c|c|}
\hline & & & \multicolumn{5}{|c|}{ Estr_socio_ocupacional } & \multirow[b]{2}{*}{ Total } \\
\hline & & & 1 Alto & 2 Médio-Alto & 3 Médio & 4 Médio-baixo & 5 Baixo & \\
\hline \multirow{20}{*}{$\begin{array}{l}\text { Estr_socio_ocupa } \\
\text { cional_1aOcup }\end{array}$} & \multirow{4}{*}{1 Alto } & Count & 586278 & 178035 & 102732 & 45194 & 10695 & 922.934 \\
\hline & & $\begin{array}{l}\text { \% within } \\
\text { Estr socio ocupacional } 1 \text { aOcup }\end{array}$ & $63,5 \%$ & $19,3 \%$ & $11,1 \%$ & $4,9 \%$ & $1,2 \%$ & $100,0 \%$ \\
\hline & & \% within Estr_socio_ocupacional & $15,4 \%$ & $4,6 \%$ & $1,1 \%$ &, $5 \%$ & , 2\% & $3,0 \%$ \\
\hline & & $\%$ of Total & $1,9 \%$ &, $6 \%$ & ,3\% & , 1\% &, $0 \%$ & $3,0 \%$ \\
\hline & \multirow{4}{*}{$\begin{array}{l}2 \text { Médio- } \\
\text { Alto }\end{array}$} & Count & 652076 & 791759 & 396569 & 203728 & 42480 & 2.086 .612 \\
\hline & & $\begin{array}{l}\text { \% within } \\
\text { Estr_socio_ocupacional_1aOcup }\end{array}$ & $31,3 \%$ & $37,9 \%$ & $19,0 \%$ & $9,8 \%$ & $2,0 \%$ & $100,0 \%$ \\
\hline & & \% within Estr_socio_ocupacional & $17,1 \%$ & $20,4 \%$ & $4,2 \%$ & $2,4 \%$ & ,8\% & $6,8 \%$ \\
\hline & & $\%$ of Total & $2,1 \%$ & $2,6 \%$ & $1,3 \%$ &, $7 \%$ & , 1\% & $6,8 \%$ \\
\hline & \multirow[t]{4}{*}{3 Médio } & Count & 895459 & 1077192 & 2858027 & 1022135 & 95303 & 5.948 .116 \\
\hline & & $\begin{array}{l}\text { \% within } \\
\text { Estr_socio_ocupacional_1aOcup }\end{array}$ & $15,1 \%$ & $18,1 \%$ & $48,0 \%$ & $17,2 \%$ & $1,6 \%$ & $100,0 \%$ \\
\hline & & \% within Estr_socio_ocupacional & $23,5 \%$ & $27,8 \%$ & $30,6 \%$ & $11,8 \%$ & $1,9 \%$ & $19,4 \%$ \\
\hline & & $\%$ of Total & $2,9 \%$ & $3,5 \%$ & $9,3 \%$ & $3,3 \%$ &, $3 \%$ & $19,4 \%$ \\
\hline & \multirow{4}{*}{$\begin{array}{l}4 \text { Médio- } \\
\text { baixo }\end{array}$} & Count & 1134164 & 1362364 & 3273977 & 3488488 & 397475 & 9.656 .468 \\
\hline & & $\begin{array}{l}\text { \% within } \\
\text { Estr_socio_ocupacional_1aOcup }\end{array}$ & $11,7 \%$ & $14,1 \%$ & $33,9 \%$ & $36,1 \%$ & $4,1 \%$ & $100,0 \%$ \\
\hline & & \% within Estr_socio_ocupacional & $29,7 \%$ & $35,1 \%$ & $35,0 \%$ & $40,3 \%$ & $7,9 \%$ & $31,5 \%$ \\
\hline & & $\%$ of Total & $3,7 \%$ & $4,4 \%$ & $10,7 \%$ & $11,4 \%$ & $1,3 \%$ & $31,5 \%$ \\
\hline & \multirow[t]{4}{*}{5 Baixo } & Count & 544520 & 471889 & 2709743 & 3889657 & 4459457 & 12.075 .266 \\
\hline & & $\begin{array}{l}\text { \% within } \\
\text { Estr_socio_ocupacional_1aOcup }\end{array}$ & $4,5 \%$ & $3,9 \%$ & $22,4 \%$ & $32,2 \%$ & $36,9 \%$ & $100,0 \%$ \\
\hline & & $\%$ within Estr_socio_ocupacional & $14,3 \%$ & $12,2 \%$ & $29,0 \%$ & $45,0 \%$ & $89,1 \%$ & $39,3 \%$ \\
\hline & & $\%$ of Total & $1,8 \%$ & $1,5 \%$ & $8,8 \%$ & $12,7 \%$ & $14,5 \%$ & $39,3 \%$ \\
\hline \multirow{4}{*}{\multicolumn{2}{|c|}{ Total }} & Count & 3.812 .497 & 3.881 .239 & 9.341 .048 & 8.649 .202 & 5.005 .410 & 30.689 .396 \\
\hline & & $\begin{array}{l}\text { \% within } \\
\text { Estr_socio_ocupacional_1aOcup }\end{array}$ & $12,4 \%$ & $12,6 \%$ & $30,4 \%$ & $28,2 \%$ & $16,3 \%$ & $100,0 \%$ \\
\hline & & \% within Estr_socio_ocupacional & $100,0 \%$ & $100,0 \%$ & $100,0 \%$ & $100,0 \%$ & $100,0 \%$ & $100,0 \%$ \\
\hline & & $\%$ of Total & $12,4 \%$ & $12,6 \%$ & $30,4 \%$ & $28,2 \%$ & $16,3 \%$ & $100,0 \%$ \\
\hline
\end{tabular}

De forma não tanto inesperada, os resultados dos índices de mobilidade apontavam para recuperação das tendências de forte mobilidade ascendente, em níveis superiores aos verificados aos de 1996, e mais próximos aos de 1982. A fim de testar a robustez desses resultados, propôs-se ajustes ad hoc, com critérios externos, na escala socioocupacional, apurando-se novas tabelas de mobilidade e seus indicadores de mobilidade associados. Na primeira proposta, propôs-se a mudança de todas as ocupações técnicas e de supervisão dos estratos 3 e 4 para o estrato 2, além da realocação de ocupações de Gerentes (CBO 1310 e 1320) para nível 2. 
Tabela 3: Matriz de Mobilidade Social com emprego da escala modificada 1

\begin{tabular}{|c|c|c|c|c|c|c|c|c|}
\hline & & & \multicolumn{5}{|c|}{ Estr_socio_ocupacional } & \multirow[b]{2}{*}{ Total } \\
\hline & & & 1 Alto & 2 Médio-Alto & 3 Médio & 4 Médio-baixo & 5 Baixo & \\
\hline \multirow{20}{*}{$\begin{array}{l}\text { Estr_socio_ocupa } \\
\text { cional_1aOcup }\end{array}$} & \multirow[t]{4}{*}{1 Alto } & Count & 496713 & 174296 & 105713 & 40324 & 11928 & 828974 \\
\hline & & $\begin{array}{l}\text { \% within } \\
\text { Estr_socio_ocupacional_1aOcup }\end{array}$ & $59,9 \%$ & $21,0 \%$ & $12,8 \%$ & $4,9 \%$ & $1,4 \%$ & $100,0 \%$ \\
\hline & & \% within Estr_socio_ocupacional & $20,0 \%$ & $3,3 \%$ & $1,0 \%$ &, $5 \%$ & , $2 \%$ & $2,7 \%$ \\
\hline & & $\%$ of Total & $1,6 \%$ & ,6\% & $3 \%$ & , $1 \%$ & , 0\% & $2,7 \%$ \\
\hline & \multirow{4}{*}{$\begin{array}{l}2 \text { Médio- } \\
\text { Alto }\end{array}$} & Count & 330310 & 859707 & 554689 & 160020 & 38863 & 1943589 \\
\hline & & $\begin{array}{l}\text { \% within } \\
\text { Estr_socio_ocupacional_1aOcup }\end{array}$ & $17,0 \%$ & $44,2 \%$ & $28,5 \%$ & $8,2 \%$ & $2,0 \%$ & $100,0 \%$ \\
\hline & & \% within Estr_socio_ocupacional & $13,3 \%$ & $16,1 \%$ & $5,4 \%$ & $2,1 \%$ &, $8 \%$ & $6,3 \%$ \\
\hline & & $\%$ of Total & $1,1 \%$ & $2,8 \%$ & $1,8 \%$ & ,5\% & , $1 \%$ & $6,3 \%$ \\
\hline & \multirow[t]{4}{*}{3 Médio } & Count & 749432 & 1637441 & 3338017 & 1075143 & 159404 & 6959437 \\
\hline & & $\begin{array}{l}\text { \% within } \\
\text { Estr_socio_ocupacional_1aOcup }\end{array}$ & $10,8 \%$ & $23,5 \%$ & $48,0 \%$ & $15,4 \%$ & $2,3 \%$ & $100,0 \%$ \\
\hline & & \% within Estr_socio_ocupacional & $30,2 \%$ & $30,7 \%$ & $32,2 \%$ & $14,3 \%$ & $3,2 \%$ & $22,7 \%$ \\
\hline & & $\%$ of Total & $2,4 \%$ & $5,3 \%$ & $10,9 \%$ & $3,5 \%$ &, $5 \%$ & $22,7 \%$ \\
\hline & \multirow{4}{*}{$\begin{array}{l}4 \text { Médio- } \\
\text { baixo }\end{array}$} & Count & 639836 & 1756978 & 3326632 & 2846923 & 335758 & 8906127 \\
\hline & & $\begin{array}{l}\text { \% within } \\
\text { Estr_socio_ocupacional_1aOcup }\end{array}$ & $7,2 \%$ & $19,7 \%$ & $37,4 \%$ & $32,0 \%$ & $3,8 \%$ & $100,0 \%$ \\
\hline & & \% within Estr_socio_ocupacional & $25,8 \%$ & $33,0 \%$ & $32,1 \%$ & $37,8 \%$ & $6,7 \%$ & $29,0 \%$ \\
\hline & & $\%$ of Total & $2,1 \%$ & $5,7 \%$ & $10,8 \%$ & $9,3 \%$ & $1,1 \%$ & $29,0 \%$ \\
\hline & \multirow[t]{4}{*}{5 Baixo } & Count & 267960 & 903043 & 3029339 & 3417639 & 4459457 & 12077438 \\
\hline & & $\begin{array}{l}\text { \% within } \\
\text { Estr_socio_ocupacional_1aOcup }\end{array}$ & $2,2 \%$ & $7,5 \%$ & $25,1 \%$ & $28,3 \%$ & $36,9 \%$ & $100,0 \%$ \\
\hline & & \% within Estr_socio_ocupacional & $10,8 \%$ & $16,9 \%$ & $29,3 \%$ & $45,3 \%$ & $89,1 \%$ & $39,3 \%$ \\
\hline & & $\%$ of Total &, $9 \%$ & $2,9 \%$ & $9,9 \%$ & $11,1 \%$ & $14,5 \%$ & $39,3 \%$ \\
\hline \multirow{4}{*}{\multicolumn{2}{|c|}{ Total }} & Count & 2484251 & 5331465 & 10354390 & 7540049 & 5005410 & 30715565 \\
\hline & & $\begin{array}{l}\text { \% within } \\
\text { Estr_socio_ocupacional_1aOcup }\end{array}$ & $8,1 \%$ & $17,4 \%$ & $33,7 \%$ & $24,5 \%$ & $16,3 \%$ & $100,0 \%$ \\
\hline & & \% within Estr_socio_ocupacional & $100,0 \%$ & $100,0 \%$ & $100,0 \%$ & $100,0 \%$ & $100,0 \%$ & $100,0 \%$ \\
\hline & & $\%$ of Total & $8,1 \%$ & $17,4 \%$ & $33,7 \%$ & $24,5 \%$ & $16,3 \%$ & $100,0 \%$ \\
\hline
\end{tabular}

$\mathrm{Na}$ segunda proposta, outras ocupações supostamente técnicas, classificadas no estrato 3 (Agentes de Saúde, por ex) foram realocadas no estrato 2; assim como ocupações de comando, situadas no nível 2 (Tenentes, por exemplo), foram realocadas no estrato 1.

As mudanças das ocupações nas escalas não produzem mudanças muito significativas nos níveis gerais de mobilidade. Contudo, as duas escalas modificadas produzem, na análise comparativa no período de 1992 a 2014, a descontinuidades maiores na estrutura socioocupacional relativa. Há uma queda expressiva entre os anos de mudança da classificação ocupacional (2001 e 2002) da participação de ocupações dos estratos 1 e 4 e aumento correspondente nos estratos 2 e 3. Além disso, o aumento do Estrato 1 entre 2004 e 2014 é bem maior do que o apurado com a classificação anterior, em detrimento do comportamento do Estrato 2. 
Tabela 3: Matriz de Mobilidade Social com emprego da escala modificada 2

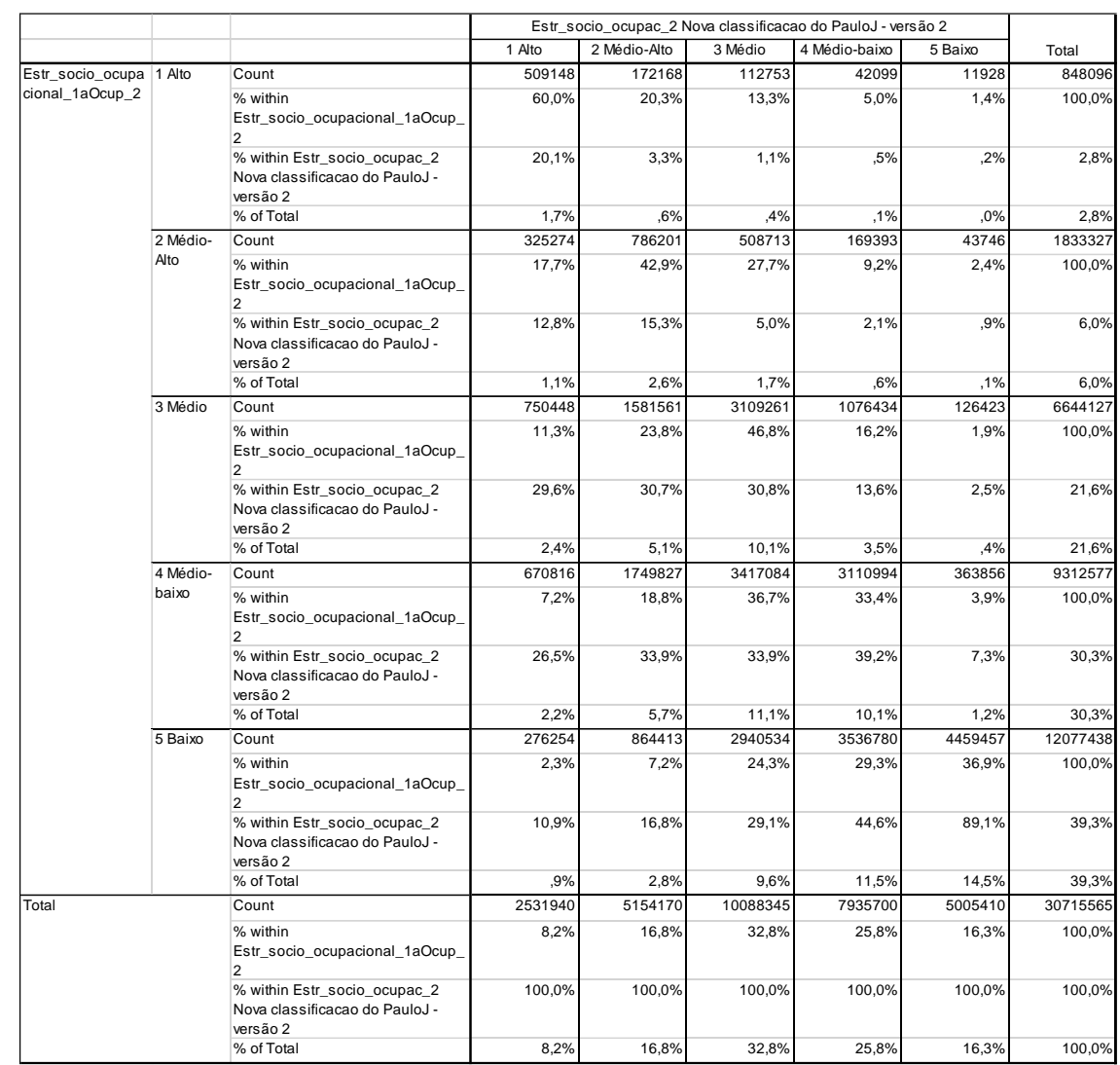

Gráfico 2: Estrutura socioocupacional em 5 estratos de ocupações modificados Brasil 1992 a 2014.

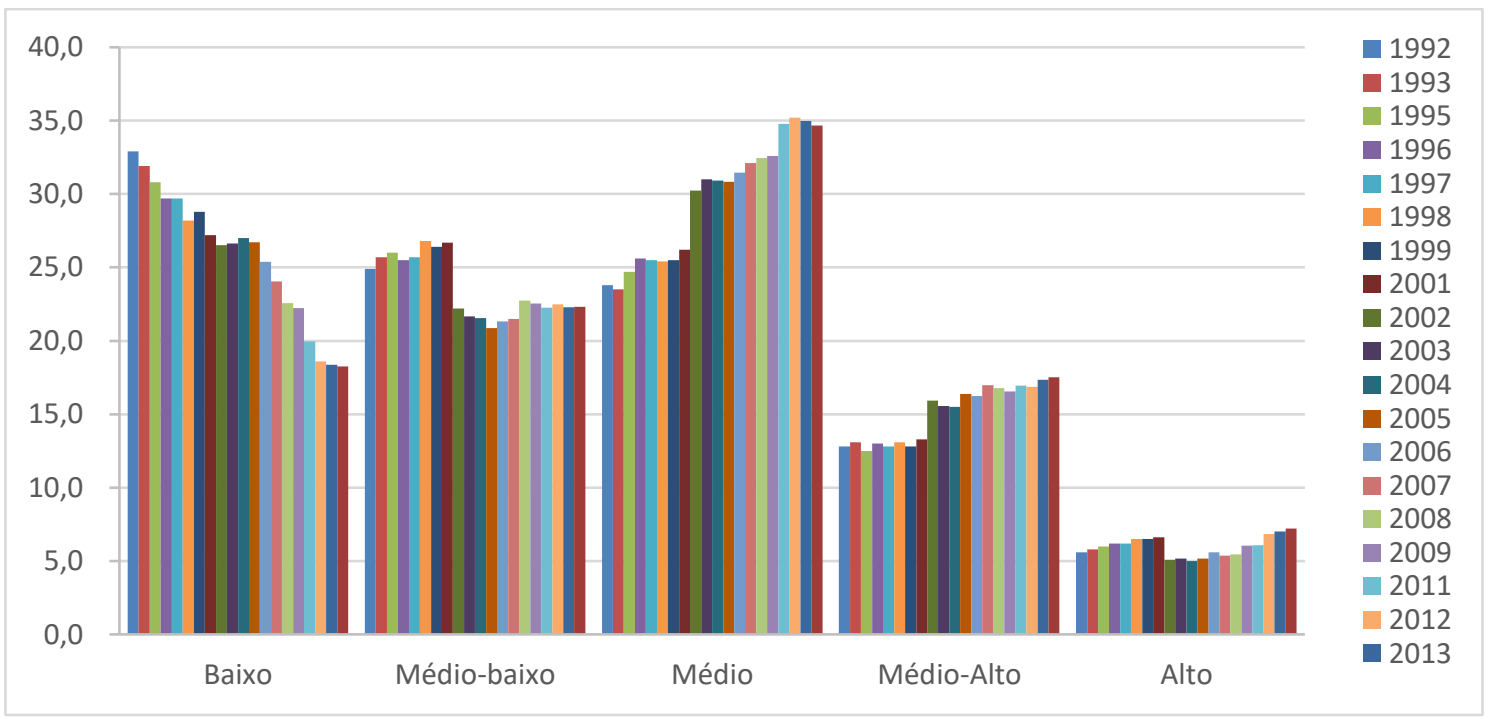


Tabela 4: Variação relativa dos Estratos Socioocupacionais em períodos

Brasil 1992 a 2014

\begin{tabular}{|c|c|c|c|c|c|c|c|}
\hline & Período & Alto & $\begin{array}{l}\text { Médio- } \\
\text { alto }\end{array}$ & Médio & $\begin{array}{l}\text { Médio- } \\
\text { baixo }\end{array}$ & Baixo & Total \\
\hline \multirow{2}{*}{ Brasil } & Var 92-01 & 44,0 & 28,5 & 31,2 & 26,7 & $-6,0$ & 17,2 \\
\hline & Var 04-14 & 67,1 & 32,4 & 33,7 & 18,4 & $-21,1$ & 16,7 \\
\hline
\end{tabular}

Decidiu-se assim, com base na avaliação comparativa da consistência - e descontinuidades- das séries 1992 a 2014 dos estratos 1 a 5, que a proposta original deveria ser a adotada. Ademais, tal proposta produz tendências de taxas de mobilidade compatíveis com as publicadas por Ribeiro (2014). 


\section{Bibliografica}

BAENINGER, Rosana. Migrações Internas no Brasil no século 21: evidências empíricas e desafios Conceituais In: CUNHA,J.M.P. Mobilidade espacial da população: desafíos teóricos e metodológicos para seu estudo. Nepo: Campinas, 2011,p.71-94.

BOUDON,R. \& BOURRICAT,F. Dicionário crítico de Sociologia. São Paulo: Ática, 2001

JANNUZZI, P.M. Mobilidade social e migração no Brasil: revisão bibliográfica e elementos empíricos para análise. Revista Brasileira de Estudos de População, v.16, p.55 - 81, 1999.

Status socioeconômico das ocupações brasileiras: índices aproximativos para 1980, 1991 e anos de 1990. Revista Brasileira de Estatística. , v.61, p.47 - 74, 2000.

Migração e Mobilidade social : migrantes no mercado de trabalho paulista. Campinas, Autores Associados/FAPESP, 2000.

Mobilidade social no contexto de adversidades crescentes do mercado de trabalho brasileiro dos anos 1990. Economia e Sociedade, Campinas, v. 11, n. 2 (19), p. 255-278, jul./dez. 2002.

As ocupações brasileiras segundo a CBO 2002: caracterização

empírica com base no Censo 2000. Revista da ABET (Online). , v.4, p.61 - 96, 2004.

PASTORE, J. Desigualdade e mobilidade social no Brasil. São Paulo: T.A.

Queiroz/EDUSP,1979.

Makron, 2000.

\& VALLE SILVA, N. Mobilidade social no Brasil. São Paulo:

RIBEIRO, C. A. C. Quarenta Anos de Mobilidade Social no Brasil. Dados, n.

55, p.641-679, 2012.

RIBEIRO, C. A. C. Mobilidade e estrutura de classes no Brasil Contemporâneo.

Sociologias, Porto Alegre, ano 16, no 37, set/dez 2014, p. 178-217.

RIBEIRO, C.A.C. Tendências da desigualdade de oportunidades no Brasil: mobilidade social e estratificação educacional. Boletim Mercado de Trabalho IPEA, 62, abri.

2017.

VIGNOLI, J.R. ¿Que definiciones, que teorias, que fuentes y que metodologias precisamos para el studio de la migración interna en la actualidad? In: CUNHA,J.M.P. Mobilidade espacial da população: desafíos teóricos e metodológicos para seu estudo. Nepo: Campinas, 2011,p.45-70. 